\title{
Mini-Review
}

\section{The first fifty microarray studies in filamentous fungi}

\author{
Andrew Breakspear and Michelle Momany \\ Department of Plant Biology, The University of Georgia, 1505 Miller Plant Sciences, Athens, \\ GA 30602, USA
}

Correspondence

Michelle Momany

momany@plantbio.uga.edu

\begin{abstract}
Microarray studies have examined global gene expression in over 20 species of filamentous fungi encompassing a wide variety of research areas. The majority have addressed aspects of metabolism or pathogenicity. Metabolic studies have revealed important differences in the transcriptional regulation of genes for primary metabolic pathways between filamentous fungi and yeast. Transcriptional profiles for genes involved in secondary metabolism have also been established. Genes required for the biosynthesis of both useful and detrimental secondary metabolites have been identified. Due to the economic, ecological and medical implications, it is not surprising that many studies have used microarray analysis to examine gene expression in pathogenic filamentous fungi. Genes involved in various stages of pathogenicity have been identified, including those thought to be important for adaptation to the host environment. While most of the studies have simulated pathogenic conditions in vitro, a small number have also reported fungal gene expression within their plant hosts. This review summarizes the first 50 microarray studies in filamentous fungi and highlights areas for future investigation.
\end{abstract}

\section{Introduction}

Microarray analysis allows the identification of differentially regulated genes from multiple distinct samples differing in environmental condition, developmental stage or genetic background. The first fungal microarray studies were reported in the budding yeast Saccharomyces cerevisiae 10 years ago (DeRisi et al., 1997; Lashkari et al., 1997). Since then microarrays have been fabricated for more than 20 species of filamentous fungi. The majority have been constructed using PCR products amplified from expressed sequence tag (EST) libraries. More recently, arrays including all predicted ORFs have enabled more comprehensive genome-wide expression studies. This review describes the earliest 50 microarray studies retrieved by a search of the Web of Science database using the query 'microarray ${ }^{\star}$ AND fungus'. The first 50 microarray studies in filamentous fungi have covered a broad spectrum of research areas, including metabolism, development, pathogenesis, symbiosis and industrial applications (Table 1).

\section{Metabolism}

Microarray studies of primary metabolism have revealed striking differences between filamentous fungi and budding yeast. Bonaccorsi et al. (2006) examined the effects of altering oxygen availability on cultures of the obligatory aerobe Trichoderma reesei. The majority of genes for the glycolytic pathway and TCA cycle were strongly repressed under oxygen-free conditions. Such a reduced expression of glycolytic genes would be insufficient to maintain anaerobic metabolism for prolonged periods without oxygen. In contrast, S. cerevisiae has been previously shown to up-regulate glycolytic genes in oxygen-free conditions, allowing metabolism to continue anaerobically (Kwast et al., 2002). Several studies have examined the effects of glucose starvation on primary metabolic genes (Chambergo et al., 2002; Maeda et al., 2004; Xie et al., 2004). In S. cerevisiae strong glucose repression of TCA cycle genes means that glucose is preferentially metabolized anaerobically, and all TCA cycle genes are strongly up-regulated during glucose starvation (DeRisi et al., 1997). In T. reesei several TCA cycle genes were only partially up-regulated while others were unaffected by glucose starvation (Chambergo et al., 2002). In Neurospora crassa and Aspergillus oryzae some TCA cycle genes were even downregulated by glucose starvation (Maeda et al., 2004; Xie et al., 2004). It is clear that the same degree of glucose repression does not operate in filamentous fungi and that aerobic respiration has a greater role in glucose metabolism by filamentous fungi than by S. cerevisiae.

Glucose starvation experiments have also revealed differences in ethanol utilization among filamentous fungi. Similar to the case in S. cerevisiae, the alcohol dehydrogenase responsible for ethanol assimilation in $T$. reese $i$ was found to be constitutively expressed before and during glucose starvation (DeRisi et al., 1997; Chambergo et al., 2002). This is in contrast to A. oryzae and N. crassa, where it was strongly induced during glucose starvation (Maeda et al., 2004; Xie et al., 2004). Glucose repression of alcohol dehydrogenase is well characterized in Aspergillus nidulans and is mediated through the transcription factor CreA (Flipphi et al., 2002). CreA is also known to repress many other metabolic genes under glucose-rich conditions, 
Table 1. The first fifty microarray studies in filamentous fungi

\begin{tabular}{|c|c|c|c|}
\hline Organism & Results $^{\star}$ and validation $\dagger$ & $\begin{array}{c}\text { Genes/ESTs } \\
\text { represented } \\
\text { and format } \ddagger\end{array}$ & Reference \\
\hline & Metabolism & & \\
\hline Aspergillus nidulans & Identified terrequinone A biosynthetic gene cluster $(\mathrm{N})$ & $9541 \S(\mathrm{Nim})$ & Bok et al. (2006) \\
\hline Trichoderma reesei & Identified oxygen regulated genes $(\mathrm{N}, \mathrm{RT})$ & 2000 (cDNA) & Bonaccorsi et al. (2006) \\
\hline Aspergillus parasiticusll & Identified aflatoxin biosynthesis genes (RT) & 5002 (cDNA) & Price et al. (2006) \\
\hline Phanerochaete chrysosporium & Obtained profiles of P450 monooxygenase genes (RT) & 190 (oligo) & Doddapaneni \& Yadav (2005) \\
\hline Aspergillus parasiticusll & Identified aflatoxin biosynthesis genes (PM) & 753 (cDNA) & Price et al. (2005) \\
\hline Aspergillus oryzae & $\begin{array}{l}\text { Obtained profiles of metabolic and industrially } \\
\text { important genes }(\mathrm{N})\end{array}$ & 2070 (cDNA) & Maeda et al. (2004) \\
\hline Fusarium verticillioides & Identified fumonisin biosynthesis genes (RT) & 716 (cDNA) & Pirttilä et al. (2004) \\
\hline Aspergillus nidulans & $\begin{array}{l}\text { Evaluated subtraction library enriched with } \\
\text { polysaccharide metabolism genes }(\mathrm{N})\end{array}$ & 728 (cDNA) & Ray et al. (2004) \\
\hline Aspergillus nidulans & $\begin{array}{l}\text { Evaluated array by examining known metabolic } \\
\text { genes }(\mathrm{PN})\end{array}$ & 3752 (cDNA) & Sims et al. (2004) \\
\hline Neurospora crassa & Identified glucose-regulated genes $(\mathrm{N})$ & 1343 (cDNA) & Xie et al. (2004) \\
\hline Trametes gallica & Identified nitrogen-regulated genes (NV) & 2596 (cDNA) & Sun et al. (2004) \\
\hline Neurospora crassa & Identified nutrient-regulated genes (NV) & 4700 (cDNA) & Aign \& Hoheisel (2003) \\
\hline Aspergillus parasiticusll & Identified aflatoxin biosynthesis genes (NV) & 753 (cDNA) & O’Brian et al. (2003) \\
\hline \multirow[t]{2}{*}{ Trichoderma reesei } & Identified glucose-regulated genes $(\mathrm{N})$ & 1151 (cDNA) & Chambergo et al. (2002) \\
\hline & Development & & \\
\hline Sordaria macrospora\# & Identified fruiting body development genes $(\mathrm{N})$ & $\sim 1000(\mathrm{cDNA})$ & Pöggeler et al. (2006) \\
\hline Neurospora crassa & Identified conidial germination genes $(\mathrm{PN})$ & 3366 (oligo) & Kasuga et al. (2005) \\
\hline Neurospora crassa & Identified MAP-kinase-regulated genes $(\mathrm{N})$ & 1343 (cDNA) & Li et al. (2005) \\
\hline Sordaria macrospora\# & Identified fruiting body development genes $(\mathrm{N})$ & $\sim 1000(\mathrm{cDNA})$ & Nowrousian et al. (2005) \\
\hline Metarhizium anisopliae & Identified ageing genes (RT) & 1730 (cDNA) & Wang et al. (2005b) \\
\hline Neurospora crassa & Identified clock-controlled genes $(\mathrm{N})$ & 1343 (cDNA) & Correa et al. (2003) \\
\hline Neurospora crassa & Identified clock-controlled genes $(\mathrm{N})$ & $\sim 1000(\mathrm{cDNA})$ & Nowrousian et al. (2003) \\
\hline \multirow[t]{2}{*}{ Neurospora crassa } & Identified light-induced genes $(\mathrm{N})$ & 1343 (cDNA) & Lewis et al. (2002) \\
\hline & Pathogenesis & & \\
\hline Aspergillus fumigatus & Identified voriconazole adaptation genes (RT) & $9516 \$(\mathrm{cDNA})$ & Ferreira et al. (2006) \\
\hline Fusarium graminearum & $\begin{array}{l}\text { Evaluated array by analysing fungal samples } \\
\text { in vitro and in planta (NV) }\end{array}$ & $\sim 14000 \$$ (Affy) & Güldener et al. (2006) \\
\hline Uromyces fabae & Identified parasitic growth genes $(\mathrm{PN})$ & $512(\mathrm{cDNA})$ & Jakupović et al. (2006) \\
\hline Gibberella zeae & $\begin{array}{l}\text { Evaluated subtraction library enriched with } \\
\text { sexual reproduction genes }(\mathrm{N})\end{array}$ & 291 (cDNA) & Lee et al. (2006) \\
\hline $\begin{array}{l}\text { Fusarium oxysporum } \mathrm{f} \text {. } \\
\text { sp. vasinfectum }\end{array}$ & Identified pathogenic genes (RT) & 6000 (cDNA) & McFadden et al. (2006) \\
\hline Gibberella zeae & Identified perithecium development genes (RT) & 1550 (cDNA) & Qi et al. (2006) \\
\hline Blumeria graminis & Identified development and pathogenic genes (RT) & 2027 (cDNA) & Both et al. (2005a) \\
\hline Blumeria graminis & $\begin{array}{l}\text { Obtained profiles of metabolic genes during } \\
\text { infection (RT) }\end{array}$ & 2027 (cDNA) & Both et al. (2005b) \\
\hline $\begin{array}{l}\text { Fusarium oxysporum } \mathrm{f} \\
\text { sp. lycopersici }\end{array}$ & Identified nitrogen-responsive genes $(\mathrm{N})$ & 1000 (cDNA) & Divon et al. (2005) \\
\hline Metarhizium anisopliae & Identified host-specific pathogenic genes (RT) & 837 (cDNA) & Freimoser et al. (2005) \\
\hline Fusarium species $\dagger \dagger$ & $\begin{array}{l}\text { Evaluated array designed to identify Fusarium } \\
\text { species (N/A) }\end{array}$ & 57 (DNA) & Nicolaisen et al. (2005) \\
\hline Aspergillus fumigatus & Identified temperature-regulated genes (NV) & $9516 \$(\mathrm{cDNA})$ & Nierman et al. (2005) \\
\hline Metarhizium anisopliae & $\begin{array}{l}\text { Identified pathogenic and saprophytic adaptation } \\
\text { genes (SL) }\end{array}$ & 1730 (cDNA) & Wang et al. (2005a) \\
\hline Metarhizium anisopliae & Identified host-specific pathogenic genes (NV) & 1730 (cDNA) & Wang \& Leger (2005) \\
\hline Cryphonectria parasitica & Identified specific hypovirus-responsive genes (RT) & 2200 (cDNA) & Allen \& Nuss (2004a) \\
\hline Cryphonectria parasitica & $\begin{array}{l}\text { Identified mitochondrial hypovirulence-regulated } \\
\text { genes (RT) }\end{array}$ & 2200 (cDNA) & Allen \& Nuss (2004b) \\
\hline
\end{tabular}


Table 1. cont.

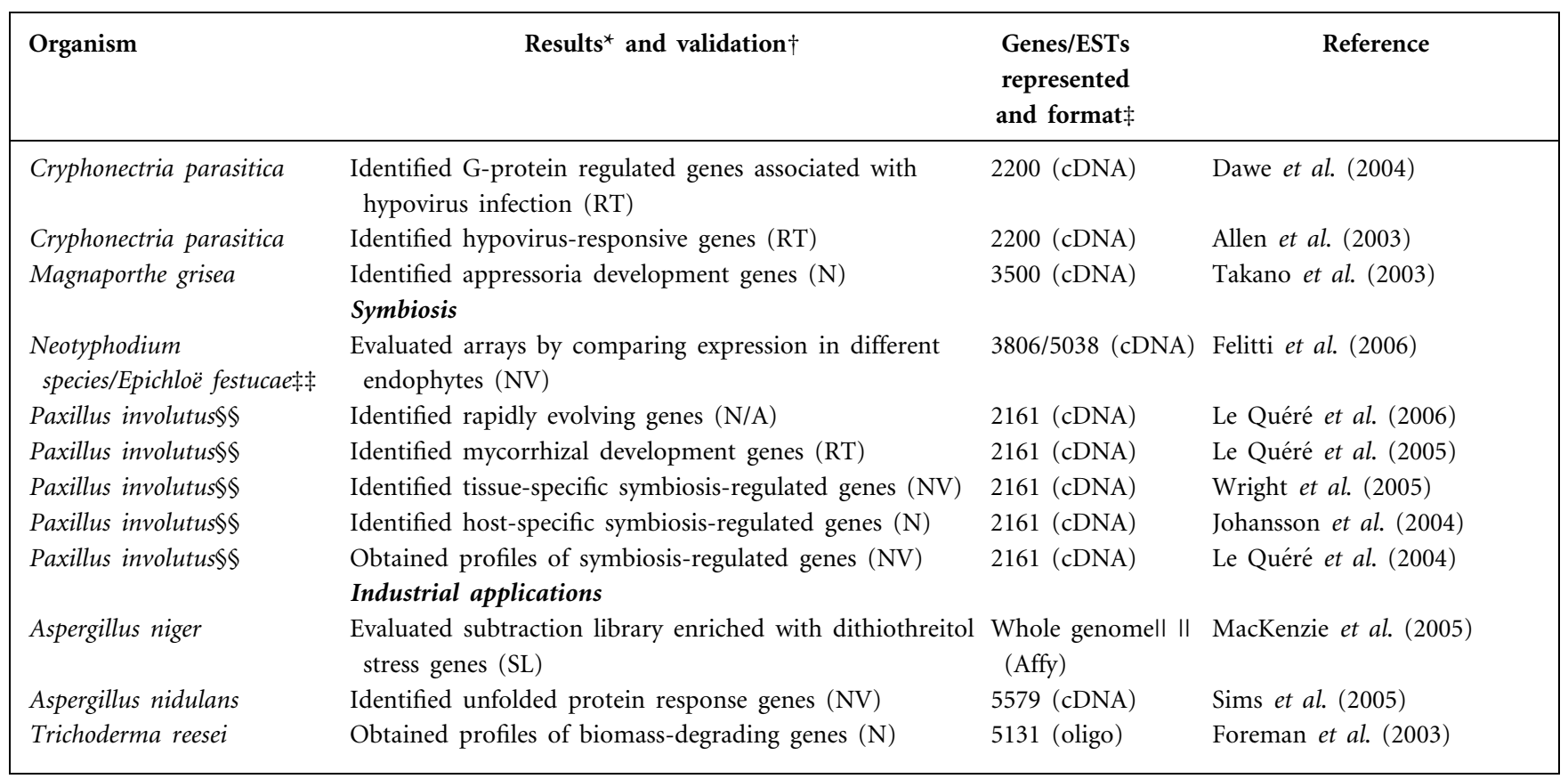

*Further details can be found in the text.

$\dagger$ Microarray studies are often validated by comparing expression data for a small number of genes (5-10) with results obtained from another analytical method. In general, the results obtained from the microarray studies in this review correlated well with Northern or real-time quantitative PCR data. The method used for validation is given in parentheses: N, Northern analysis; PN, compared to previously published Northern; PM, compared to previously published microarray; RT, real-time quantitative PCR; SL, compared to genes isolated from subtraction library; N/A, not applicable; NV, no validation reported.

¥Affy, Affymetrix GeneChips; DNA, short oligonucleotides based on genomic DNA; cDNA, PCR amplicons on coated glass slides; Nim, Nimblegen arrays; oligo, long oligonucleotides.

§icroarray based on whole genome.

IIAspergillus flavus cDNA microarry hybridized with Aspergillus parasiticus probes.

IPhanerochaete chrysosporium cDNA microarry hybridized with Trametes gallica probes.

\#Neurospora crassa cDNA microarry hybridized with Sordaria macrospora probes.

${ }^{*}$ Microarray represents ESTs from both Fusarium oxysporum f. sp. vasinfectum and its host Gossypium hirsutum.

$\dagger \dagger$ Microarray represents a variety of Fusarium species that infect cereal grain.

¥†Two microarrays were used, one representing 3806 Neotyphodium coenophialum and Neotyphodium lolii genes and the other representing 4195 Neotyphodium and 920 Epichloë festucae genes.

$\$ \$$ Microarray represents ESTs from both Paxillus involutus and its ectomycorrhizal partner Betula pendula.

II IFurther information is available to academic groups and non-profit organizations (hans.roubos@dsm.com).

playing a major role in carbon catabolite repression (Flipphi et al., 2003). Sims et al. (2004) evaluated an A. nidulans microarray by examining the expression of previously characterized metabolic genes. CreA-mediated glucose repression was observed in cells which were shifted from ethanol to glucose. Aign \& Hoheisel (2003) also explored the effects of carbon source, comparing cultures grown on minimal or acetate medium to complete medium. The majority of differentially regulated genes were up-regulated on minimal or acetate medium, with one-third representing central metabolic genes.

In contrast to $S$. cerevisiae and other yeasts, filamentous fungi produce a vast array of secondary metabolites.
Secondary metabolite genes are often clustered together in the genome and regulated by a common transcription factor. The nuclear protein LaeA is a global regulator of secondary metabolite clusters in A. nidulans. Bok et al. (2006) compared expression in an laeA deletion $(\Delta l a e A)$ mutant and a wild-type strain to identify clusters controlled by LaeA. Genome mining identified one particular cluster in which all five genes were down-regulated in the $\Delta l a e A$ strain. Analysis of the secondary metabolite produced by the cluster revealed the antitumour compound terrequinone $\mathrm{A}$, a metabolite not previously described in A. nidulans.

Aflatoxins are highly carcinogenic secondary metabolites which contaminate a wide variety of crops, including maize. 
AflR regulates transcription of genes required for the biosynthesis of aflatoxin in Aspergillus parasiticus ( $\mathrm{Yu}$ et al., 1996). Price et al. (2006) compared expression of an aflR deletion mutant $(\Delta a f l R)$ with its parental wild-type. Microarray analysis revealed 23 genes up-regulated in the wild-type. These included three genes outside the aflatoxin pathway cluster which were previously not associated with aflatoxin biosynthesis. Earlier studies investigated the influence of fungal development (O'Brian et al., 2003) and culture conditions (Price et al., 2005) on aflatoxin production. Price et al. (2005) compared expression in culture conditions conducive and not conducive to aflatoxin production. Cluster analysis was used to identify genes with similar expression profiles to known aflatoxin biosynthesis genes. A similar strategy was employed to identify genes associated with fumonisin biosynthesis in the plant pathogen Fusarium verticillioides (Pirttilä et al., 2004). Nineteen genes had similar expression profiles to known fumonisin genes. Six of these were homologous to genes with characterized functions including the high-affinity (Zrtlp) and low-affinity (Msc2p) zinc transporters in $S$. cerevisiae.

\section{Development}

Filamentous fungi provide excellent models to study development in multicellular eukaryotic organisms. Kasuga et al. (2005) used microarrays to investigate the genetic mechanisms important for conidial germination in $N$. crassa. Expression was compared at distinct morphological events such as isotropic swelling, germ tube emergence and the formation of a mycelial mat. A total of 1287 genes were differentially regulated and the majority grouped into seven clusters with similar expression patterns. Transcriptional profiles were consistent with previously published data and corresponded with known biochemical processes associated with conidial germination. The results were also compared to previous microarray studies detailing spore germination in the dimorphic fungus Ustilago maydis (Zahiri et al., 2005) and the amoeba Dictyostelium discoideum (Xu et al., 2004). Of the 1287 genes differentially regulated in $N$. crassa, 25 were orthologous to those regulated in $U$. maydis and 16 orthologous to those regulated in D. discoideum. Kasuga et al. (2005) concluded that the transcriptional similarities between these diverse organisms suggest that mechanisms of spore germination could be evolutionarily conserved.

Nowrousian et al. (2005) examined the complex developmental process of fruiting body formation in Sordaria macrospora. Expression profiles of three developmental mutants (pro1, pro11 and pro22) unable to produce mature perithecia were compared to a wild-type strain. Genes encoding proteins associated with cell wall biogenesis and fungal development were significantly down-regulated in the mutant strains. Sexual development in S. macrospora was further examined by Pöggeler et al. (2006), who identified genes regulated by the mating type gene smta-1. Since smta1 is also unable to produce mature perithecia it is not surprising that 10 of the genes identified were also differentially expressed in the three pro mutants (Nowrousian et al., 2005; Pöggeler et al., 2006). The N. crassa MAP kinase MAK-2 and its target PP-1 are also required for sexual development (Li et al., 2005). Li et al. (2005) compared expression in a wild-type to $\Delta m a k-2$ and $\triangle p p-1$ deletion mutants. Interestingly, two of the genes upregulated in both $\Delta m a k-2$ and $\Delta p p-1$ are rhythmically expressed circadian-clock-controlled genes (Bell-Pedersen et al., 1996).

Circadian-clock-controlled genes have been characterized in cyanobacteria, fungi, plants and animals (Young \& Kay, 2001). Sleep patterns, hormone cycles and body temperature in humans and photosynthesis in plants rely on the rhythmic expression of clock-controlled genes (Takahashi \& Zatz, 1982). Temperature and light keep them in synchrony with the environment. Circadian rhythms are important for development in N. crassa (Sargent et al., 1966). Conidiation peaks at the transition from dark to light or from cold to warm, a time known as subjective dawn. Several studies have used microarrays to identify novel clock-controlled genes in N. crassa (Correa et al., 2003; Nowrousian et al., 2003). Expression was compared at various time points throughout the circadian cycle and clustering used to identify rhythmically expressed genes with similar expression patterns. The genes identified coded for proteins with diverse functions, including protein synthesis, metabolism and development (Correa et al., 2003; Nowrousian et al., 2003).

The products of $f r q, w c-1$ and $w c-2$ form an auto-regulatory negative feedback cycle known as the FRQ/WCC oscillator that is required for circadian regulation in $N$. crassa (Nowrousian et al., 2003). Nowrousian et al. (2003) used microarray analysis to demonstrate that the FRQ/WCC oscillator is responsive to temperature. Of the 27 clockcontrolled genes identified in the study, 14 were also temperature regulated. However, temperature regulation of all 14 genes was lost in an $f r q$ knockout mutant $(\Delta f r q)$. This result suggests that the FRQ/WCC oscillator mediates temperature-induced synchrony of $N$. crassa clock-controlled genes. In addition to its role as a circadian regulator, WC-1 regulates all known blue-light-responsive clockindependent genes (Lewis et al., 2002). Lewis et al. (2002) used microarrays to identify genes that are induced by light and genes that are induced by overexpression of WC-1. Since only four of the 22 light-induced genes identified are also induced by WC-1 overexpression it was concluded that elevated levels of WC- 1 alone are not sufficient to activate all light-responsive genes.

\section{Pathogenesis}

Microarray studies have addressed fungal pathogens of both plants and animals. Many plant-pathogenic fungi rely on the formation of appressoria (swollen hyphae required for anchorage and penetration) to infect their hosts. Turgor pressure generated by the appressorium combined with 
enzyme degradation allows these fungi to penetrate the plant cuticle. Takano et al. (2003) aimed to identify genes important for appressorium formation in Magnaporthe grisea using cultures grown on appressoria-inducing GelBond medium. Sixty-seven genes were up-regulated in developing appressoria compared to vegetative mycelia. Interestingly, transcripts for 19 of these genes were present at higher levels in dormant conidia compared to vegetative mycelia. These included a homologue of a characterized virulence gene from Collectotrichum gloeosporioides (cap20) (Hwang et al., 1995) and $\Delta^{24}$-sterol C-methyl transferase. Sterol biosynthesis has also been linked to pathogenicity in C. gloeosporioides (Kim et al., 2002) and the insect pathogen Metarhizium anisopliae (Wang et al., 2005a). The results suggest that a pool of pre-existing conidial mRNA may contain transcripts important for pathogenesis.

The Blumeria graminis cap20 homologue was also significantly up-regulated in developing appressoria (Both et al., 2005a). Gene expression was examined in this plant pathogen as part of a wider study of fungal development during infection of barley (Both et al., 2005a, b). RNA was collected from eight stages of infection representing the complete asexual cycle of the fungus. Ten other potential pathogenicity genes were identified whose expression correlated with the cap20 homologue. Five were homologous to previously characterized virulence genes and five were homologous to genes with previously proposed pathogenicity roles. Microarray analysis of fungal genes expressed in planta has also revealed pathogenic genes in the rust fungus Uromyces fabae (Jakupovic et al., 2006) and the cotton pathogen Fusarium oxysporum f. sp. vasinfectum (McFadden et al., 2006). McFadden et al. (2006) identified a putative oxidoreductase gene, with homologues in both pathogenic and non-pathogenic fungi, which was expressed 500-fold higher in planta compared to vegetative mycelia. Furthermore, in planta expression of the gene in pathogenic isolates was greater than that in nonpathogenic isolates. Expression was also positively correlated with vascular browning, a characteristic symptom of Fusarium wilt infection (McFadden et al., 2006).

Cryphonectria parasitica is the causative agent of chestnut blight and infects chestnut trees worldwide. Hypoviruses have been shown to reduce virulence in C. parasitica and are important for its biological control (Allen et al., 2003). Allen et al. (2003) compared fungal expression in a strain of $C$. parasitica infected with the hypovirus CHV1-EP713 to a virus-free parent. A group of 295 differentially regulated genes belonged to a variety of functional groups including metabolism, development and cell wall growth. A homologue of M. grisea Mst12, a transcription factor regulating infectious hyphal growth, was amongst those downregulated in the virus-infected strain. A major connection between viral hypovirulence and G-protein-mediated signal transduction was established when expression of two mutant strains $(\Delta c p g-1$ and $\Delta c p g b-1)$ missing $\mathrm{G} \alpha$ and $\mathrm{G} \beta$ G-protein subunits was examined (Dawe et al., 2004).
Almost half (45\%) of the genes previously shown to be regulated by hypovirus infection were also differentially expressed in at least one of the G-protein mutants compared to the parental wild-type.

Microarray analysis has also been used to investigate infection in animal pathogens. Perhaps the best-studied animal pathogens are dimorphic, not filamentous, and so are not described here (recent microarray studies in Candida albicans include Hromatka et al., 2005; Sandovsky-Losica et al., 2006; Lepak et al., 2006). The human pathogen Aspergillus fumigatus must adapt to its host temperature for successful infection. Nierman et al. (2005) examined the thermotolerance of the fungus by comparing expression at temperatures representing pathogenic $\left(37^{\circ} \mathrm{C}\right)$ and nonpathogenic $\left(30^{\circ} \mathrm{C}\right.$ and $\left.48^{\circ} \mathrm{C}\right)$ environments. Many genes encoding heat-shock proteins were differentially regulated, suggesting their importance for temperature adaptation. Voriconazole is used to treat patients infected with $A$. fumigatus. However, its use is often limited by drug resistance (Ferreira et al., 2006). Ferreira et al. (2006) examined the ability of the fungus to adapt to this antifungal agent. Cluster analysis revealed one group of rapidly up-regulated genes containing an $\mathrm{ABC}$ multidrug transporter and a glutathione $S$-transferase. Both genes are thought to have roles in voriconazole detoxification and are potentially required for adaptation to the drug.

Adaptation by the insect pathogen Metarhizium anisopliae during infection of its host has also been addressed using microarray analysis. M. anisopliae must adapt to both the cuticle and haemolymph of its host (Wang et al., 2005a). Microarray analysis revealed subsets of genes associated with its adaptation which included genes for cell wall reorganization and adaptors to osmotic stress (Wang et al., 2005a). M. anisopliae was also observed to adapt specifically to different insect hosts (Freimoser et al., 2005). One particular hydrophobin (a family of proteins which mediate fungal attachment to hydrophobic surfaces) was up-regulated on medium containing cockroach or beetle cuticle but unaffected on medium containing gypsy moth cuticle. The differential regulation of this and other hydrophobins (Freimoser et al., 2005) further links cell wall changes to fungal adaptation.

\section{Symbiosis}

Ectomycorrhizae (ECM) are ecologically important symbiotic associations consisting of both plant and fungal tissue. While the fungus gains a source of photosynthetic sugars, the plant benefits from improved nutrient uptake. Several studies have investigated global expression during the development of ECM between Betula pendula (birch) and Paxillus involutus. Both fungal and plant genes specifically regulated in the ectomycorrhizal symbiosis have been identified.

Fungal genes specifically regulated in the ECM have a variety of putative functions. A predicted fungal hexose transporter 
was up-regulated during the entire course of ECM development (Le Quéré et al., 2005). This is significant because the fungal partner in the symbiotic relationship receives sugars from the plant (Söderström et al., 1988). Le Quéré et al. (2005) speculated that the putative heoxose transporter is a candidate for fungal hexose assimilation in the ECM tissue. Homologues of proteins in the electron transport chain were also highly up-regulated during ECM development (Le Quéré et al., 2005). However, the lowered expression of the TCA cycle enzyme malate dehydrogenase suggested that the potential increase in respiration was not connected to glucose metabolism. Fungal genes with putative functions in the secretory pathway were also differentially expressed in ECM tissue (Johansson et al., 2004; Wright et al., 2005). Interestingly, many were expressed more strongly in rhizomorphs, tubular hyphal aggregates that function in the transport of nutrients to the ECM root tissue, than in ECM root tissue itself (Wright et al., 2005).

Consistent with the fungal partner, ECM-regulated plant genes also have a variety of putative functions. Many predicted metabolic genes, including several encoding TCA cycle and electron transport chain enzymes, were downregulated in ECM tissue (Johansson et al., 2004). Johansson et al. (2004) suggested that the reduced expression of these enzymes indicated a lower rate of aerobic respiration in ECM compared to free-living roots. Genes with putative roles in plant defence were also differentially expressed in ECM tissue (Johansson et al., 2004; Le Quéré et al., 2005). While many were up-regulated in early stages of ECM development they were not significantly regulated in later stages (Le Quéré et al., 2005).

Recently microarrays have been fabricated for the grass fungal endophytes Neotyphodium coenophialum, Neotyphodium lolii and Epichloë festucae (Felitti et al., 2006). Several proof-of-concept hybridizations were reported comparing different saprophytic growth conditions (Felitti et al., 2006). The microarrays should allow further insight into the mutualistic associations between plants and fungi.

\section{Industrial applications}

Filamentous fungi are used extensively in industrial fermentations. Maeda et al. (2004) used microarray analysis to examine the expression of industrially important enzymes secreted by $A$. oryzae. A variety of solid-state culture conditions containing different waste biomass materials were compared. Growth on wheat bran induced expression of the richest set of industrially important hydrolytic enzymes and validated its current industrial use. In a similar study Foreman et al. (2003) examined the regulation of commercially important biomass-degrading enzymes in $T$. reesei. The majority of putative and characterized biomass-degrading enzymes represented on the array were up-regulated in both sophorose- and lactose-supplemented cultures (Foreman et al., 2003).
Filamentous fungi are also used as hosts to produce commercially important heterologous proteins. Industrialscale production of heterologous proteins often results in lower yields than those achieved for native proteins. A molecular understanding of the secretory system is important for improving efficiency of recombinant protein secretion. Sims et al. (2005) used microarray analysis to identify genes associated with recombinant protein production in A. nidulans. Expression was compared in a recombinant bovine-chymosin-producing strain and its wild-type parent. The study revealed a variety of secretionrelated genes involved with the unfolded protein response (UPR). Manipulation of UPR genes in Aspergillus species has been shown to improve yields of heterologous proteins (Moralejo et al., 2001; Conesa et al., 2002). MacKenzie et al. (2005) aimed to identify further UPR genes in Aspergillus niger using the secretion blocker DTT, thought to mimic the effects of recombinant protein secretion. Subtractive hybridization and microarray analysis were used to identify genes regulated by DTT. While a number of stressresponsive genes were identified they did not appear to be related to the UPR, suggesting that DTT does not specifically induce the UPR.

\section{Future prospects: the next fifty}

Microarray analysis is still in its infancy and much potential remains for further study in all of the areas covered in this review. Of the studies investigating pathogenesis only a few have reported expression in plant hosts and none have reported expression in animal hosts. There is certainly much potential for further investigation of in-host expression, provided that complications of obtaining sufficient quantities of fungal RNA and interference from host RNA can be overcome. It would also be of great interest to compare genes induced during pathogenic interactions to those induced in symbiotic relationships. Such a comparison may distinguish genes associated with host adaptation from those related to pathogenicity. Of the 50 studies detailed in this report it is surprising that none have investigated the cell cycle. Microarray studies in both budding and fission yeast have identified many periodically expressed cell cycle genes not previously connected to the cell cycle (Spellman et al., 1998; Bähler, 2005; Peng et al., 2005). There is great potential for similar studies in filamentous fungi, particularly in $A$. nidulans, where many cell cycle mutants are available.

Comparing expression profiles of different species of filamentous fungi may provide insight into how this diverse group of fungi has evolved. Interestingly, microarrays have only been fabricated for three filamentous species of basidiomycetes (Paxillus involutus, Phanerochaete chrysosporium and Uromyces fabae) and none represent filamentous zygomycetes. The potential for comparative functional genomics within filamentous fungi would greatly benefit from more microarrays of filamentous members from these groups. Several studies have described successful crossspecies hybridizations in closely related species of filamentous fungi. An Affymetrix GeneChip recently fabricated for 
the plant pathogen F. graminearum has been shown to efficiently detect genes from four other closely related species of Fusarium (Güldener et al., 2006). Cross-species analysis could dramatically increase the number of studies available for comparative functional genomics.

The recent completion of several fungal genome projects and subsequent fabrication of whole-genome microarrays has further fuelled the potential for global gene expression studies in filamentous fungi. The first 50 microarray studies in filamentous fungi were published over a four-year period. With the explosion of fungal microarray studies the next 50 will appear much faster.

\section{Acknowledgements}

Microarray studies in our lab are supported by US Department of Energy Biosciences grant DE-FG02-97ER20275 to M. M. Given the scope of this review, we might have unintentionally omitted microarray studies that should have been included. We sincerely apologize to the authors of any microarray studies in filamentous fungi that we have not mentioned.

\section{References}

Aign, V. \& Hoheisel, J. D. (2003). Analysis of nutrient-dependent transcript variations in Neurospora crassa. Fungal Genet Biol 40, 225-233.

Allen, T. D. \& Nuss, D. L. (2004a). Specific and common alterations in host gene transcript accumulation following infection of the chestnut blight fungus by mild and severe hypoviruses. J Virol 78, 4145-4155.

Allen, T. D. \& Nuss, D. L. (2004b). Linkage between mitochondrial hypovirulence and viral hypovirulence in the chestnut blight fungus revealed by cDNA microarray analysis. Eukaryot Cell 3, 1227-1232.

Allen, T. D., Dawe, A. L. \& Nuss, D. L. (2003). Use of cDNA microarrays to monitor transcriptional responses of the chestnut blight fungus Cryphonectria parasitica to infection by virulenceattenuating hypoviruses. Eukaryot Cell 2, 1253-1265.

Bähler, J. (2005). Cell-cycle control of gene expression in budding and fission yeast. Annu Rev Genet 39, 69-94.

Bell-Pedersen, D., Shinohara, M. L., Loros, J. J. \& Dunlap, J. C. (1996). Circadian clock-controlled genes isolated from Neurospora crassa are late night- to early morning-specific. Proc Natl Acad Sci U S A 93, 13096-13101.

Bok, J. W., Hoffmeister, D., Maggio-Hall, L. A., Murillo, R., Glasner, J. D. \& Keller, N. P. (2006). Genomic mining for Aspergillus natural products. Chem Biol 13, 31-37.

Bonaccorsi, E. D., Ferreira, A. J. S., Chambergo, F. S., Ramos, S. P., Mantovani, M. C., Farah, J. P. S., Sorio, C. S., Gombert, A. K., Tonso, A. \& El-Dorry, H. (2006). Transcriptional response of the obligatory aerobe Trichoderma reesei to hypoxia and transient anoxia: implications for energy production and survival in the absence of oxygen. Biochemistry 45, 3912-3924.

Both, M., Eckert, S. E., Csukai, M., Muller, E., Dimopoulos, G. \& Spanu, P. D. (2005a). Transcript profiles of Blumeria graminis development during infection reveal a cluster of genes that are potential virulence determinants. Mol Plant Microbe Interact 18, 125-133.

Both, M., Csukai, M., Stumpf, M. P. H. \& Spanu, P. D. (2005b). Gene expression profiles of Blumeria graminis indicate dynamic changes to primary metabolism during development of an obligate biotrophic pathogen. Plant Cell 17, 2107-2122.

Chambergo, F. S., Bonaccorsi, E. D., Ferreira, A. J. S., Ramos, A. S. P., Junior, J. R. F., Abrahao-Neto, J., Farah, J. P. S. \& El-Dorry, H. (2002). Elucidation of the metabolic fate of glucose in the filamentous fungus Trichoderma reesei using expressed sequence tag (EST) analysis and cDNA microarrays. J Biol Chem 277, 13983-13988.

Conesa, A., Jeenes, D., Archer, D. B., van den Hondel, C. A. \& Punt, P. J. (2002). Calnexin overexpression increases manganese peroxidase production in Aspergillus niger. Appl Environ Microbiol 68, 846-851.

Correa, A., Lewis, A. Z., Greene, A. V., March, I. J., Gomer, R. H. \& Bell-Pedersen, D. (2003). Multiple oscillators regulate circadian gene expression in Neurospora. Proc Natl Acad Sci U S A 100, 13597-13602.

Dawe, A. L., Segers, G. C., Allen, T. D., McMains, V. C. \& Nuss, D. L. (2004). Microarray analysis of Cryphonectria parasitica $\mathrm{G} \alpha$ - and G $\beta \gamma$ signalling pathways reveals extensive modulation by hypovirus infection. Microbiology 150, 4033-4043.

DeRisi, J. L., lyer, V. R. \& Brown, P. O. (1997). Exploring the metabolic and genetic control of gene expression on a genomic scale. Science 278, 680-686.

Divon, H. H., Rothan-Denoyes, B., Davydov, O., Di Pietro, A. \& Fluhr, R. (2005). Nitrogen-responsive genes are differentially regulated in planta during Fusarium oxysporum f. sp. lycopersici infection. Mol Plant Pathol 6, 459-470.

Doddapaneni, H. \& Yadav, J. S. (2005). Microarray-based global differential expression profiling of P450 monooxygenases and regulatory proteins for signal transduction pathways in the white rot fungus Phanerochaete chrysosporium. Mol Genet Genomics 274, 454-466.

Felitti, S., Shields, K., Ramsperger, M., Tian, P., Sawbridge, T., Webster, T., Logan, E., Erwin, T., Forster, J. \& other authors (2006). Transcriptome analysis of Neotyphodium and Epichlö̈ grass endophytes. Fungal Genet Biol 43, 465-475.

Ferreira, M. E. D., Malavazi, I., Savoldi, M., Brakhage, A. A., Goldman, M. H. S., Kim, H. S., Nierman, W. C. \& Goldman, G. H. (2006). Transcriptome analysis of Aspergillus fumigatus exposed to voriconazole. Curr Genet 50, 32-44.

Flipphi, M., Kocialkowska, J. \& Felenbok, B. (2002). Characteristics of physiological inducers of the ethanol utilization (alc) pathway in Aspergillus nidulans. Biochem J 364, 25-31.

Flipphi, M., van de Vondervoort, P. J., Ruijter, G. J., Visser, J., Arst, H. N., Jr \& Felenbok, B. (2003). Onset of carbon catabolite repression in Aspergillus nidulans. Parallel involvement of hexokinase and glucokinase in sugar signaling. J Biol Chem 278, 11849-11857.

Foreman, P. K., Brown, D., Dankmeyer, L., Dean, R., Diener, S., Dunn-Coleman, N. S., Goedegebuur, F., Houfek, T. D., England, G. J. \& other authors (2003). Transcriptional regulation of biomassdegrading enzymes in the filamentous fungus Trichoderma reesei. J Biol Chem 278, 31988-31997.

Freimoser, F. M., Hu, G. \& St Leger, R. J. (2005). Variation in gene expression patterns as the insect pathogen Metarhizium anisopliae adapts to different host cuticles or nutrient deprivation in vitro. Microbiology 151, 361-371.

Güldener, U., Seong, K. Y., Boddu, J., Cho, S., Trail, F., Xu, J., Adam, G., Mewes, H., Muehlbauer, G. J. \& Kistler, H. C. (2006). Development of a Fusarium graminearum Affymetrix GeneChip for profiling fungal gene expression in vitro and in planta. Fungal Genet Biol 43, 316-325.

Hromatka, B. S., Noble, S. M. \& Johnson, A. D. (2005). Transcriptional response of Candida albicans to nitric oxide and the role of the YHB1 gene in nitrosative stress and virulence. Mol Biol Cell 16, 4814-4826. 
Hwang, C. S., Flaishman, M. A. \& Kolattukudy, P. E. (1995). Cloning of a gene expressed during appressorium formation by Colletotrichum gloeosporioides and a marked decrease in virulence by disruption of this gene. Plant Cell 7, 183-193.

Jakupović, M., Heintz, M., Reichmann, P., Mendgen, K. \& Hahn, M. (2006). Microarray analysis of expressed sequence tags from haustoria of the rust fungus Uromyces fabae. Fungal Genet Biol 43, 8-19.

Johansson, T., Le Quéré, A., Ahren, D., Söderström, B., Erlandsson, R., Lundeberg, J., Uhlén, M. \& Tunlid, A. (2004). Transcriptional responses of Paxillus involutus and Betula pendula during formation of ectomycorrhizal root tissue. Mol Plant Microbe Interact 17, 202-215.

Kasuga, T., Townsend, J. P., Tian, C. G., Gilbert, L. B., Mannhaupt, G., Taylor, J. W. \& Glass, N. L. (2005). Long-oligomer microarray profiling in Neurospora crassa reveals the transcriptional program underlying biochemical and physiological events of conidial germination. Nucleic Acids Res 33, 6469-6485.

Kim, Y. K., Wang, Y., Liu, Z. M. \& Kolattukudy, P. E. (2002). Identification of a hard surface contact-induced gene in Colletotrichum gloeosporioides conidia as a sterol glycosyl transferase, a novel fungal virulence factor. Plant J 30, 177-187.

Kwast, K. E., Lai, L. C., Menda, N., James, D. T., III, Aref, S. \& Burke, P. V. (2002). Genomic analyses of anaerobically induced genes in Saccharomyces cerevisiae: functional roles of Rox1 and other factors in mediating the anoxic response. J Bacteriol 184, 250-265.

Lashkari, D. A., DeRisi, J. L., McCusker, J. H., Namath, A. F., Gentile, C., Hwang, S. Y., Brown, P. O. \& Davis, R. W. (1997). Yeast microarrays for genome wide parallel genetic and gene expression analysis. Proc Natl Acad Sci U S A 94, 13057-13062.

Lee, S. H., Lee, S., Choi, D., Lee, Y. W. \& Yun, S. H. (2006). Identification of the down-regulated genes in a mat1-2-deleted strain of Gibberella zeae, using cDNA subtraction and microarray analysis. Fungal Genet Biol 43, 295-310.

Lepak, A., Nett, J., Lincoln, L., Marchillo, K. \& Andes, D. (2006). Time course of microbiologic outcome and gene expression in Candida albicans during and following in vitro and in vivo exposure to fluconazole. Antimicrob Agents Chemother 50, 1311-1319.

Le Quéré, A., Schützendübel, A., Rajashekar, B., Canbäck, B., Hedh, J., Erland, S., Johansson, T. \& Tunlid, A. (2004). Divergence in gene expression related to variation in host specificity of an ectomycorrhizal fungus. Mol Ecol 13, 3809-3819.

Le Quéré, A., Wright, D. P., Söderström, B., Tunlid, A. \& Johansson, T. (2005). Global patterns of gene regulation associated with the development of ectomycorrhiza between birch (Betula pendula Roth.) and Paxillus involutus (Batsch) Fr. Mol Plant Microbe Interact 18, 659-673.

Le Quéré, A., Eriksen, K. A., Rajashekar, B., Schützenbübel, A., Canbäck, B., Johansson, T. \& Tunlid, A. (2006). Screening for rapidly evolving genes in the ectomycorrhizal fungus Paxillus involutus using cDNA microarrays. Mol Ecol 15, 535-550.

Lewis, Z. A., Correa, A., Schwerdtfeger, C., Link, K. L., Xie, X., Gomer, R. H., Thomas, T., Ebbole, D. J. \& Bell-Pedersen, D. (2002). Overexpression of White Collar-1 (WC-1) activates circadian clockassociated genes, but is not sufficient to induce most light-regulated gene expression in Neurospora crassa. Mol Microbiol 45, 917-931.

Li, D., Bobrowicz, P., Wilkinson, H. H. \& Ebbole, D. J. (2005). A mitogen-activated protein kinase pathway essential for mating and contributing to vegetative growth in Neurospora crassa. Genetics 170, 1091-1104.

MacKenzie, D. A., Guillemette, T., Al-Sheikh, H., Watson, A. J., Jeenes, D. J., Wongwathanarat, P., Dunn-Coleman, N. S., van Peij, N. \& Archer, D. B. (2005). UPR-independent dithiothreitol stress-induced genes in Aspergillus niger. Mol Genet Genomics 274, 410-418.
Maeda, H., Sano, M., Maruyama, Y., Tanno, T., Akao, T., Totsuka, Y., Endo, M., Sakurada, R., Yamagata, Y. \& other authors (2004). Transcriptional analysis of genes for energy catabolism and hydrolytic enzymes in the filamentous fungus Aspergillus oryzae using cDNA microarrays and expressed sequence tags. Appl Microbiol Biotechnol 65, 74-83.

McFadden, H. G., Wilson, I. W., Chapple, R. M. \& Dowd, C. (2006). Fusarium wilt (Fusarium oxysporum f. sp. vasinfectum) genes expressed during infection of cotton (Gossypium hirsutum). Mol Plant Pathol 7, 87-101.

Moralejo, F. J., Watson, A. J., Jeenes, D. J., Archer, D. B. \& Martin, J. F. (2001). A defined level of protein disulfide isomerase expression is required for optimal secretion of thaumatin by Aspergillus awamori. Mol Genet Genomics 266, 246-253.

Nicolaisen, M., Justesen, A. F., Thrane, U., Skouboe, P. \& Holmstrom, K. (2005). An oligonucleotide microarray for the identification and differentiation of trichothecene producing and non-producing Fusarium species occurring on cereal grain. J Microbiol Methods 62, 57-69.

Nierman, W. C., Pain, A., Anderson, M. J., Wortman, J. R., Kim, H. S., Arroyo, J., Berriman, M., Abe, K., Archer, D. B. \& other authors (2005). Genomic sequence of the pathogenic and allergenic filamentous fungus Aspergillus fumigatus. Nature 438, 1151-1156.

Nowrousian, M., Duffield, G. E., Loros, J. J. \& Dunlap, J. C. (2003). The frequency gene is required for temperature-dependent regulation of many clock-controlled genes in Neurospora crassa. Genetics 164, 923-933.

Nowrousian, M., Ringelberg, C., Dunlap, J. C., Loros, J. L. \& Kuck, U. (2005). Cross-species microarray hybridization to identify developmentally regulated genes in the filamentous fungus Sordaria macrospora. Mol Genet Genomics 273, 137-149.

O’Brian, G. R., Fakhoury, A. M. \& Payne, G. A. (2003). Identification of genes differentially expressed during aflatoxin biosynthesis in Aspergillus flavus and Aspergillus parasiticus. Fungal Genet Biol 39, 118-127.

Peng, X., Karuturi, R. K., Miller, L. D., Lin, K., Jia, Y., Kondu, P., Wang, L., Wong, L., Liu, E. T. \& other authors (2005). Identification of cell cycle-regulated genes in fission yeast. Mol Biol Cell 16, 1026-1042.

Pirttilä, A. M., McIntyre, L. M., Payne, G. A. \& Woloshuk, C. P. (2004), Expression profile analysis of wild-type and fecl mutant strains of Fusarium verticillioides during fumonisin biosynthesis. Fungal Genet Biol 41, 647-656.

Pöggeler, S., Nowrousian, M., Ringelberg, C., Loros, J. J., Dunlap, J. C. \& Kuck, U. (2006). Microarray and real-time PCR analyses reveal mating type-dependent gene expression in a homothallic fungus. Mol Genet Genomics 275, 492-503.

Price, M. S., Shannon, B. C. B., Sabrina, T. B., Robert, A. K. B. \& Payne, G. A. (2005). Aflatoxin conducive and non-conducive growth conditions reveal new gene associations with aflatoxin production. Fungal Genet Biol 42, 506-518.

Price, M. S., Yu, J. J., Nierman, W. C., Kim, H. S., Pritchard, B., Jacobus, C. A., Bhatnagar, D., Cleveland, T. E. \& Payne, G. A. (2006). The aflatoxin pathway regulator AfIR induces gene transcription inside and outside of the aflatoxin biosynthetic cluster. FEMS Microbiol Lett 255, 275-279.

Qi, W. H., Chil, K. \& Trail, F. (2006). Microarray analysis of transcript accumulation during perithecium development in the filamentous fungus Gibberella zeae (anamorph Fusarium graminearum). Mol Genet Genomics 276, 87-100.

Ray, A., Macwana, S., Ayoubi, P., Hall, L. T., Prade, R. \& Mort, A. J. (2004). Negative subtraction hybridization: an efficient method to isolate large numbers of condition-specific cDNAs. BMC Genomics 5,22 
Sandovsky-Losica, H., Chauhan, N., Calderone, R. \& Segal, E. (2006). Gene transcription studies of Candida albicans following infection of HEp2 epithelial cells. Med Mycol 44, 329-334.

Sargent, M. L., Briggs, W. R. \& Woodward, D. O. (1966). Circadian nature of a rhythm expressed by an invertaseless strain of Neurospora crassa. Plant Physiol 41, 1343-1349.

Sims, A. H., Robson, G. D., Hoyle, D. C., Oliver, S. G., Turner, G., Prade, R. A., Russell, H. H., Dunn-Coleman, N. S. \& Gent, M. E. (2004). Use of expressed sequence tag analysis and cDNA microarrays of the filamentous fungus Aspergillus nidulans. Fungal Genet Biol 41, 199-212.

Sims, A. H., Gent, M. E., Lanthaler, K., Dunn-Coleman, N. S., Oliver, S. G. \& Robson, G. D. (2005). Transcriptome analysis of recombinant protein secretion by Aspergillus nidulans and the unfolded-protein response in vivo. Appl Environ Microbiol 71, 2737-2747.

Söderström, B., Finlay, R. D. \& Read, D. J. (1988). The structure and function of the vegetative mycelium of ectomycorrhizal plants. 4. Qualitative analysis of carbohydrate contents of mycelium interconnecting host plants. New Phytol 109, 163-166.

Spellman, P. T., Sherlock, G., Zhang, M. Q., lyer, V. R., Anders, K., Eisen, M. B., Brown, P. O., Botstein, D. \& Futcher, B. (1998). Comprehensive identification of cell cycle-regulated genes of the yeast Saccharomyces cerevisiae by microarray hybridization. Mol Biol Cell 9, 3273-3297.

Sun, X., Jiang, M. F., Li, X. \& Zhang, Y. Z. (2004). Rapid screening of expressed genes of Trametes gallica by cDNA microarray. Prog Biochem Biophys 31, 356-360.

Takahashi, J. S. \& Zatz, M. (1982). Regulation of circadian rhythmicity. Science 217, 1104-1111.

Takano, Y., Choi, W. B., Mitchell, T. K., Okuno, T. \& Dean, R. A. (2003). Large scale parallel analysis of gene expression during infection-related morphogenesis of Magnaporthe grisea. Mol Plant Pathol 4, 337-346.
Wang, C. S. \& Leger, R. J. S. (2005). Developmental and transcriptional responses to host and nonhost cuticles by the specific locust pathogen Metarhizium anisopliae var. acridum. Eukaryot Cell 4, 937-947.

Wang, C. S., Hu, G. \& St Leger, R. J. (2005a). Differential gene expression by Metarhizium anisopliae growing in root exudate and host (Manduca sexta) cuticle or hemolymph reveals mechanisms of physiological adaptation. Fungal Genet Biol 42, 704-718.

Wang, C. S., Butt, T. M. \& St Leger, R. J. (2005b). Colony sectorization of Metarhizium anisopliae is a sign of ageing. Microbiology 151, 3223-3236.

Wright, D. P., Johansson, T., Le Quéré, A., Soderstrom, B. \& Tunlid, A. (2005). Spatial patterns of gene expression in the extramatrical mycelium and mycorrhizal root tips formed by the ectomycorrhizal fungus Paxillus involutus in association with birch (Betula pendula) seedlings in soil microcosms. New Phytol 167, 579-596.

Xie, X., Wilkinson, H. H., Correa, A., Lewis, Z. A., Bell-Pedersen, D. \& Ebbole, D. J. (2004). Transcriptional response to glucose starvation and functional analysis of a glucose transporter of Neurospora crassa. Fungal Genet Biol 41, 1104-1119.

Xu, Q., Ibarra, M., Mahadeo, D., Shaw, C., Huang, E., Kuspa, A., Cotter, D. \& Shaulsky, G. (2004). Transcriptional transitions during Dictyostelium spore germination. Eukaryot Cell 3, 1101-1110.

Young, M. W. \& Kay, S. A. (2001). Time zones: a comparative genetics of circadian clocks. Nat Rev Genet 2, 702-715.

Yu, J. H., Butchko, R. A., Fernandes, M., Keller, N. P., Leonard, T. J. \& Adams, T. H. (1996). Conservation of structure and function of the aflatoxin regulatory gene aflR from Aspergillus nidulans and A. flavus. Curr Genet 29, 549-555.

Zahiri, A. R., Babu, M. R. \& Saville, B. J. (2005). Differential gene expression during teliospore germination in Ustilago maydis. Mol Genet Genomics 273, 394-403. 